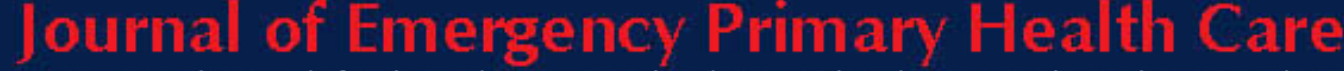

An International elournal of Prehospital care Research, Education, clinical Practice, Policy and Service Delivery

ISSN 1447-4999

Policy and Service Delivery

\title{
THE PREHOSPITAL COMMUNITY-VOLUNTEER MODEL HAS A PLACE IN RURAL AUSTRALIA
}

\author{
Peter O'Meara,
}

$\mathrm{PhD}$, MPublicPolicy, BHealthAdmin, - Lecturer, Monash University School of Rural Health

\section{Objectives}

Australian ambulance services rely on the community-volunteer model of prehospital care in many rural areas. The aim of this study was to conceptually describe the model as it operates in rural settings.

\section{Methods}

Soft Systems Methodology (SSM) was used to describe and critically appraise an abstract prehospital community-volunteer model within the context of rural Australia. The philosophical starting point was that local prehospital services should be self-reliant and autonomous. SSM was used to structure the elements of prehospital systems and the relationships between them into metaphors and pictures for analysis.

\section{Results}

The major characteristic of the prehospital community-volunteer model is the relatively uncomplicated processes used to deliver services. Key elements are a knowledgeable and empowered community, a dispatch system with local knowledge, adequate physical resources to meet community expectations, a volunteer-based staffing system, and direct communication with local health professionals.

Culturally, the community-volunteer model has a very strong rural character, with opportunity for health professional, emergency worker and local community member involvement. This may be as a volunteer ambulance officer or as a participant in the local governance of the service.

\section{Conclusions}

The prehospital community-volunteer model is a strong and resilient model in communities where the relationship between the ambulance service and the community is based on a socially constructed framework. Advanced technology, rules, systems, procedures and policies are unable to sustain a community-volunteer ambulance service. In contrast to other models, it is held together through stories of the past, rituals and myths.

Prehospital community-volunteer models will continue to be important providers of prehospital services in rural Australia. Successful community-volunteer ambulance services need to be integrated into a local urgent care system.

\section{Keywords: prehospital; rural; model volunteer}




\section{Introduction}

The aim of the study was to describe and analyse a number of abstract prehospital models, including the community-volunteer model of ambulance service delivery. This model is a long-established prehospital model in rural Australia and elsewhere. Its operation in Australia has been neglected on the assumption that volunteer systems will whither and die.

Soft Systems Methodology (SSM) was used to build this and four other models from different philosophical perspectives in recognition of the diverse socio-political environment in which rural ambulance services operate. While the other models - competitive, sufficing, expert and practitioner - are all reliant on paid paramedics who have received advanced training and education, they share with the community-volunteer model a range of elements or components that have been identified elsewhere as making up emergency ambulance systems. ${ }^{1-5}$ These disparate elements include human resources, equipment, education and training of staff, medical input, research, communication systems and planning.

Rural Ambulance Victoria employs its own version of the community-volunteer model in small and remote communities. It operates 29 community ambulance stations and employs 370 Ambulance Community Officers on a casual basis at these and other small stations to supplement full-time staff. It also has 67 active branch station auxiliaries to raise funds and maintain community support. A significant difference between this approach and the abstract community-volunteer model is the corporate support provided from Rural Ambulance Victoria. This is in the form of a modern communications network, training and education programs, medical advice, counselling and peer support, and the supply of vehicles and equipment. ${ }^{6}$

The Western Australian and South Australian ambulance services have respectively 1,687 and 1,477 volunteer staff, that constitute a large percentage of their total workforces. ${ }^{7}$ The Tasmanian Ambulance Service also has an estimated 380 volunteers. ${ }^{8}$ It is also well to note, that most existing ambulance services in Australia can trace their origins back to voluntary organizations. ${ }^{9}$ The findings of this study provide support for the continued existence of volunteer-based ambulance services; they illustrate the sense of connection between smalltown medical practitioners, country hospitals and their local ambulance services.

Calls for improved support and assistance to volunteer staff and stations indicate that ambulance services have not always applied the lessons learnt in other emergency services, such as the Country Fire Authority in Victoria and the State Emergency Service in New South Wales. ${ }^{6,8,10}$ Ambulance service managers may need to ask themselves about the impact of their actions or inactions on the social construction of the organizational reality in small rural communities.

\section{Methods}

The data collection methods employed included a review of the prehospital and emergency management literature, collection of empirical data, questionnaires to stakeholders, interviews with prehospital experts, a focus group of ambulance service managers, and the observation of similar models. Based on these data, suggestions were developed for the future refinement and management of the community-volunteer model of service delivery in contemporary rural settings.

The research setting was the Australian state of Victoria, where in March 1999, the five major rural ambulance regions were amalgamated into Rural Ambulance Victoria. The amalgamation provided the opportunity to study models of prehospital service delivery in rural settings during a time of major organizational change. 
A systems approach, Soft Systems Methodology (SSM), was used to make sense of these data collected because of its ability to deal with ill-structured or 'messy-problem' contexts. ${ }^{11}$ This research approach was useful because it allowed an exploration of a diversity of viewpoints as part of the decision-making and intervention process. ${ }^{12}$ The significant advantage of a systems approach over classical management approaches is its ability to take account of both the logic and the broader cultural context of problem situations. It incorporates mechanisms that allow for continuous feedback loops between what is described as the 'logic-based stream of analysis' and the 'stream of cultural analysis'. ${ }^{13}$ At a practical level, the process is an iterative one that incorporates four main stages: developing a 'rich picture' of the problematical situation; developing systems models of one or more aspects of the problem situation; comparing the system models with the real world; and identifying opportunities for improvement. $^{14}$

\section{Defining the problem}

In the first instance, a general picture of the provision of prehospital services in rural Victoria was established by examining the strengths and weaknesses of current models in terms of what key stakeholders believe works well and those areas that could be improved. Questionnaires, sent to health professionals and selected members of the community in rural Victoria, were used to collect these data. From this analysis, the problem situation was described in terms of the ambulance service's organizational structure, the processes used to deliver services, and the cultural and technological influences on the delivery of prehospital care. The latter includes the educational and technological influences that drive innovation and development. The socio-political situation in small rural towns was examined through a focus on links between ambulance paramedics, nurses, medical practitioners and health services. This led to an analysis of how problems are currently managed.

\section{Model development}

The second stage of the research was the development of the community-volunteer model. This involved a selection of aspects of the prehospital system that were particularly worthy of further exploration. The main considerations were:

- Whether there are opportunities for major improvement?

- Are there aspects of the problem that are poorly understood?

- Is it politically wise to explore a specific aspect and is now an opportune time to consider change?

- Are there differences of opinion about current or future actions?

The major steps in this development of the model were the naming and defining of prehospital systems to identify the main inputs that are transformed into useful outputs. This identified the key elements of the systems such as service delivery processes, environmental constraints, clients of the system, service providers, and the holders of power and influence. Underpinning all of these is the dominant 'worldview' that provides an explanation of the reason the services are worth providing. In this case, it is the view that communities should be self-reliant and autonomous in the provision of prehospital services.

The systems were then modelled in terms of activities, links and controls as the basis for discussion of the possibilities for change. Performance monitoring and control mechanisms were also explored to turn abstract thoughts into a practical model. The main players were described according to their roles as clients, problem-solvers and problem-owners. For 
instance, the local volunteer staff and committee of management are considered to be the main problem-solvers, while the local community and health professionals are often the problem-owners with the power to change how services are provided. The interacting elements of social systems such as roles, norms and values were described to help appreciate how the different perspectives of health professionals and members of the community influence the development and implementation of new prehospital models.

\section{Comparisons with reality}

To make the community-volunteer model comprehensible to a wider audience, it was modelled further using metaphors and 'rich pictures' based on an understanding of its core aims and objectives. The model and its associated metaphors are designed to stimulate discussion and debate about the changes that could improve the delivery of rural prehospital services and the accommodations that will be required between conflicting interests for the actions-to-improve to be taken. This future dialogue, comparing the model with reality, has the potential to form the beginnings of future transition and implementation strategies.

\section{Findings}

The community-volunteer model is a community controlled and operated ambulance service that aims to meet the prehospital expectations of a local community. A major practical departure between the community-volunteer model and other prehospital models is the relatively uncomplicated transformation processes it uses to deliver services. Key elements of the model are a knowledgeable and empowered community, a dispatch system with local knowledge, adequate physical resources to meet community expectations, a volunteer-based staffing system, and direct communication with and subservience to local health professionals.

This low level of complexity is best illustrated in its 'patient pathway' (Figure 1). Patients follow a direct path from the scene of their unplanned incident to their local hospital and medical practitioner. Decisions regarding treatment or patient destination are made within the local health system setting following the directives of local medical practitioners. Volunteer ambulance officers have little autonomy or clinical discretion compared to full-time paramedics who have been trained in advanced assessment and clinical interventions. 
Figure 1: $\quad$ Patient Pathway for Community-Volunteer Model ${ }^{6}$

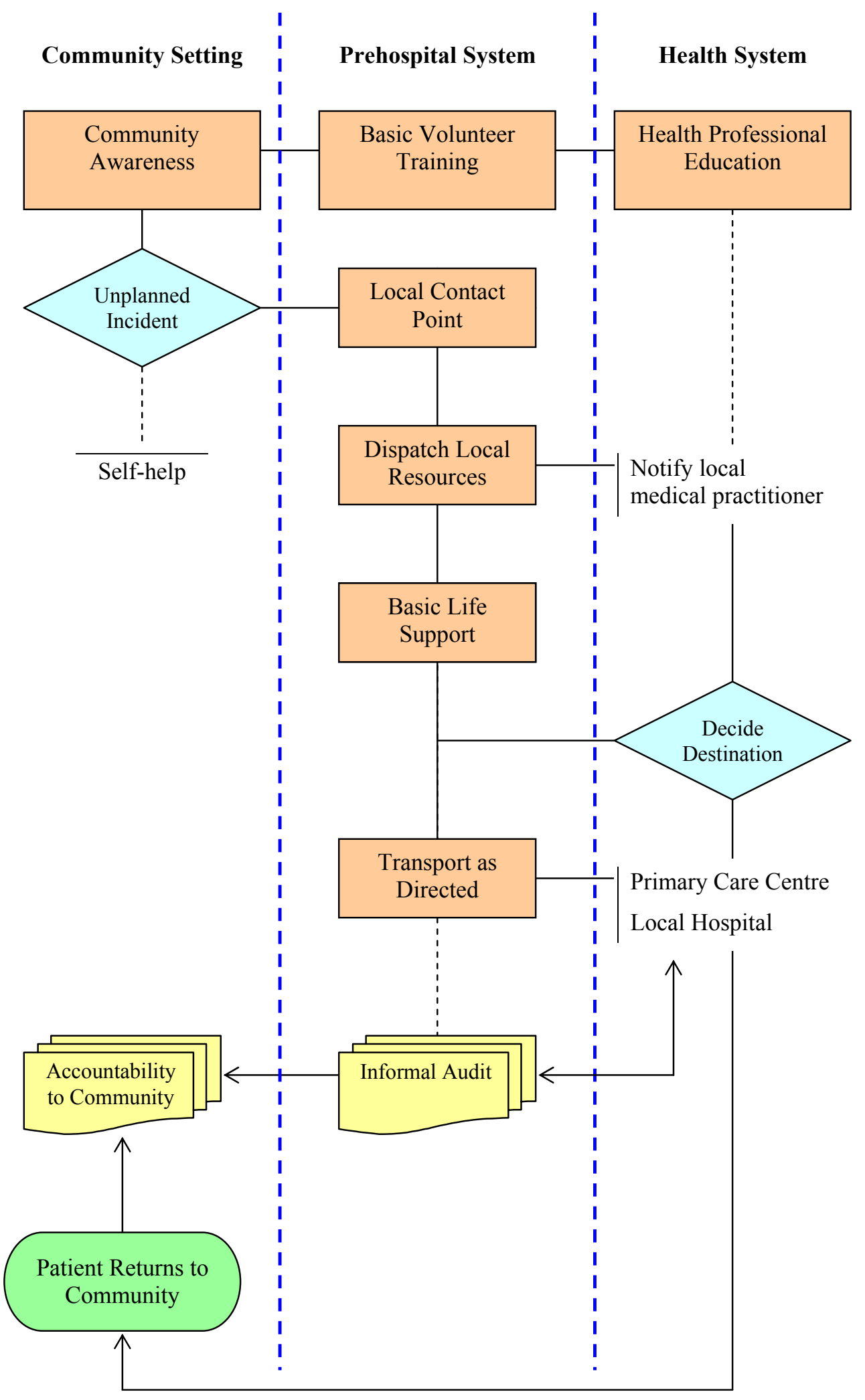


Local governance and management, as opposed to regional and state-wide control, is another distinctive characteristic of the community-volunteer model. Community-controlled committees of management can dominate the tone and direction of the services provided through fund raising activities, the recruitment and retention of staff, and the extent of the monitoring and quality improvement strategies they adopt. Both my direct experience of managing community-volunteer models and their theoretical basis supports the notion that they can be either innovative or very resistant to change. ${ }^{1}$

Ensuring an adequate supply of trained and motivated staff to volunteer-based systems is an ongoing challenge that is shared with other emergency services. Positive factors that have been identified in this regard include the provision of good management, training, recognition, organizational support and activity, and internal communication networks. ${ }^{8,10,15}$ An environmental factor that places pressure on the community-volunteer model is, the growing competition for volunteer staff amongst emergency services in rural areas; this emerging factor may not always assist efforts to develop and maintain teamwork and cooperation between kindred health and emergency services.

A related personnel issue is the maintenance of competency amongst volunteer staff, who may have small individual caseloads and limited opportunity to maintain their skills or develop satisfactory clinical judgement. In some locations in rural Victoria this risk is minimized through the employment of fully qualified staff to take leadership and training roles in those areas that would otherwise be totally reliant on volunteers or Ambulance Community Officers. This strategy is particularly valuable in those locations without medical practitioners, who would ordinarily be expected to assume leadership roles in relation to prehospital care. Community-volunteer models without links to regional or state ambulance services are highly dependent on local medical practitioners as role models and for practical support and advice. For example, voluntary staff may lack adequate training in how to handle the ethical problem of dealing with confidentiality in small communities. ${ }^{6}$

The activities described in the rich picture (Figure 2) combine with the system elements and relationships to achieve outputs in the form of transformation processes that address the community's expectation that they will have access to adequately resourced ambulance services that are able to respond quickly to their needs with well-trained staff who behave in a professional manner. ${ }^{16}$ The management processes required to ensure this include maintenance of infrastructure such as vehicles and communication, staffing and dispatch, education and training, and maintenance of standards.

The community-volunteer model has a very strong rural character, with ample opportunity for health professionals, emergency workers and members of the local community to be involved. This may be as a volunteer ambulance officer or as a participant in the local governance of the service; all citizens have the opportunity to influence the setting of organizational priorities and objectives. This attribute contrasts with some other models, where priority setting is firmly in the hands of the 'experts'. 
Figure 2: Rich Picture of Community- Volunteer Model ${ }^{6}$

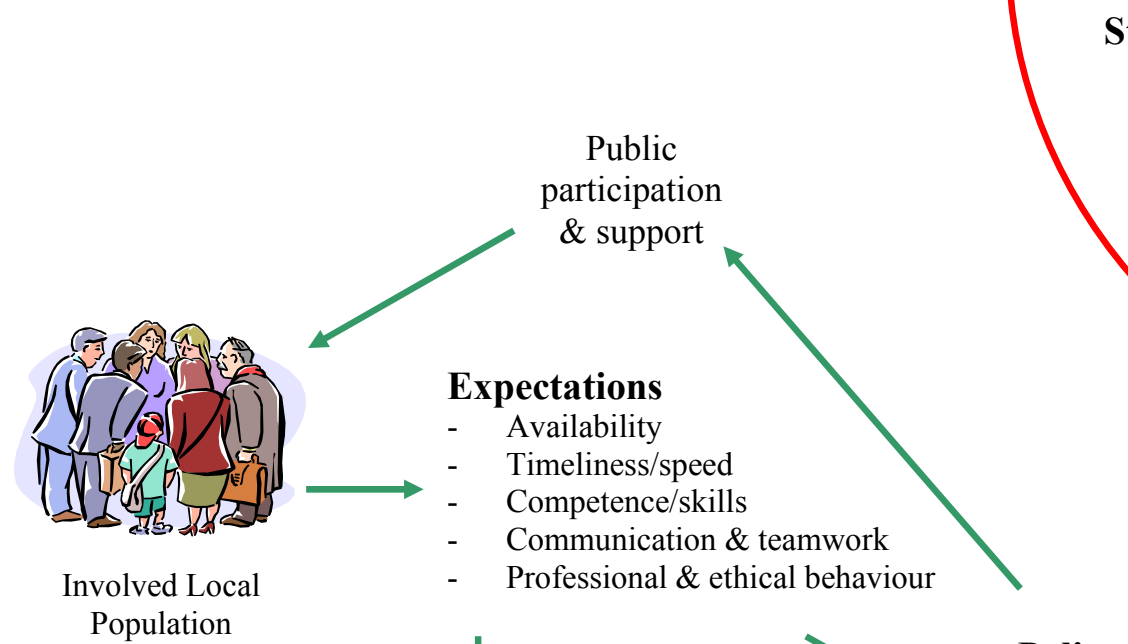

\section{Stakeholders/Owners}

- Local community

- Local medical practitioners

- Local hospital

- Volunteer staff

- Subscribers/members

Population

- Professional \& ethical behaviour

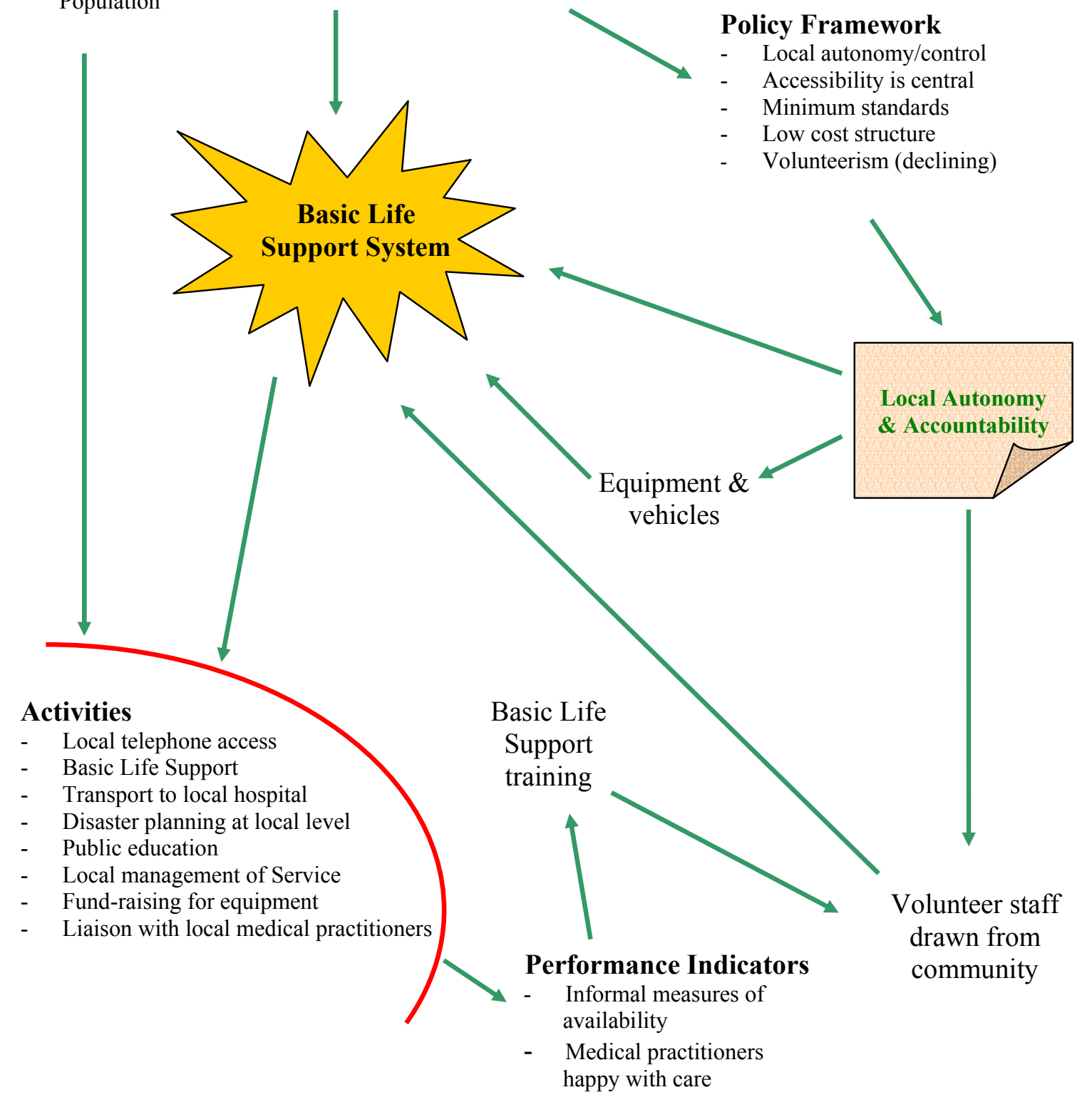




\section{Discussion}

The community-volunteer model is located within the functionalist paradigm and uses a cultural metaphor to describe how self-reliant communities have local control over ambulance activities. Its strength is derived from a belief that the community itself is taking responsibility for the provision of its own emergency prehospital care. This may be through the activation of local health professionals and/or community volunteers to provide a viable service, with or without active government support.

Advanced technology, rules, systems, procedures and policies are unable to sustain a community-based ambulance service. After all, volunteers do not join an organization to fill in heaps of forms. ${ }^{10}$

Where other models emphasize the importance of organizational structures and processes, the community model is held together through stories of the past, rituals and myths. It focuses on the human influences that create and shape organized activity by influencing the ideologies, values, beliefs, language, norms, ceremonies and other social practices that shape and guide organized action. ${ }^{17}$ The Country Fire Authority in Victoria (CFA), with 67,000 volunteer members, uses this management approach very effectively. The CFA has identified the motivating factors and disincentives amongst its volunteers, and makes a concerted effort to account for them in their management practices. ${ }^{15}$

Tapping into the cultural essence of a community-volunteer model to implement change can be a very powerful strategy. However, it can also be a dangerous ploy if culture is reduced to a discrete set of variables such as values, beliefs, stories, norms and rituals. Morgan ${ }^{17}$ points out that, culture is a lived experience and cannot be controlled in the sense that some management writers advocate.

The model operates most effectively in a viable community that has the scope to support community organizations. Being able to draw on community members for organizational support and for the supply of volunteer staff is an important attribute of the model. ${ }^{1}$ The ability of the community-volunteer model to foster local autonomy and community participation provides its greatest strength and potentially its greatest threat. Local enthusiasts can be either driving forces behind the provision of good services or the destroyers of service delivery systems through poor management. Examples from North America illustrate how community-based ambulance services have a tendency to fragment and disintegrate as a result of internally generated strains and tensions. ${ }^{1}$ Systems without good management and a nurturing environment run the risk of self-destructing. The lack of central support and a reliance on a narrow section of the community to maintain and develop the service delivery system in an essentially voluntary capacity is inherently risky, and a poor strategy for sustainability.

Successful community-volunteer ambulance services, need to be integrated into a local urgent care system that has the support of a broad coalition of stakeholders such as medical practitioners, nurses, emergency services workers, local government and a local hospital. ${ }^{18,19}$ Unless these supports and strong professional linkages with other ambulance professionals are in place, the community-volunteer model is vulnerable to operating as a sub-standard system using outmoded equipment and deviating from accepted professional practices.

Even though successful volunteer systems recruit from talented and successful members of the community, they generally lack the professional training and education of mainstream staff. $^{1,14,20}$ As a result of their limited education and training opportunities in prehospital care, they may lack any professional career path in prehospital care. To overcome these potential weaknesses, community-volunteer models need strong standards frameworks built into them, 
with strong medical audit mechanisms. They also need to have a strong sense of organizational strength, with community members being proud to be members. ${ }^{1}$

The difficulty of recruiting and retaining volunteer staff in rural areas is of particular concern to the community-volunteer model because of its potentially adverse impact on the responsiveness of the services offered. The challenge of recruiting and retaining staff is particularly acute in volunteer systems where financial factors are irrelevant.

"Volunteers, whose motivation is not financial, need a stake in their organisation. They not only want to know what is going on, they want to influence proceedings. "10

Factors that make staff recruitment problems more pressing are ageing populations in many rural areas and higher workforce participation rates of spouses. These and other factors mean that the ability to commit the time and energy for training and service is becoming increasing limited for current and potential volunteer staff. Other factors impacting on human resources include increased personal risks, perceptions of increased personal liability, lack of enlightened leadership, inadequate medical participation, and limited funding for training, equipment and supplies.

The report card of the community-volunteer model is mixed. The model's performance is very strong in terms of access and efficiency, making it popular with community activists who value local autonomy and control. Funding bodies are attracted to the efficiency of using predominately volunteer labour, rather than professionally employed paramedics. Unions and professional associations of ambulance staff express a different perspective and point to the poor effectiveness of volunteer systems. ${ }^{21}$ Its local focus opens it to the risk of compromising access in the wider area or region. The model may not, for example, develop linkages with adjoining ambulance services for the purposes of mutual aid. ${ }^{1,20}$ In most of rural Victoria, this risk is minimized with the employment of fully-qualified staff to take leadership and training roles in remote areas that would otherwise be reliant on volunteer/Ambulance Community Officers.

In spite of its critics, community-volunteer ambulance systems are unlikely to disappear from rural and remote communities. Small communities lack the resources to support models that rely on paid staff or they are unable to attract and retain suitably qualified staff. In Victoria, one independent community-volunteer ambulance service continues to exist against the odds in two small towns. It is a low-cost service, which enjoys the support of its community and the local medical community. ${ }^{6}$ On balance a mixed model such as the one operating within Rural Ambulance Victoria is likely to be more sustainable than the traditionally independent community-volunteer model that is reliant on a few committed individuals for survival. 


\section{References}

1. Reich, J. 'The rural route to success: Comparing EMS in three Alabama counties'. Journal of Emergency Medical Services. 1991; 16: 53-56.

2. Anderson, PB. 'Rural EMS System Development: Innovative Technological Approaches', in Straub, La Vonne \& Walzer, Norman (Eds.). Rural Health Care: Innovation in a Changing Environment. Praeger, London. 1992.

3. Gallehr, JE. and Vokov, LF. 'Defining the benefits of rural emergency medical techniciandefibrillation'. Annals of Emergency Medicine. 1993; 22(10): 108-112.

4. Lynch, TG. and Georghiou, PF. 'Managing rural emergency medical services: Doing more with less' Top Emerg Med. 1995; 17(3): 1-13.

5. National Rural Health Association (USA). Rural and Frontier Emergency Medical Services Toward the Year 2000. Washington. 1997.

6. Audit Office of New South Wales. Performance Audit Report: Ambulance Service of New South Wales: readiness to respond. The Audit Office of New South Wales. Sydney. 2001.

7. Fahey, C. Walker, J. and Sleigh, A. 'Training can be a recruitment and retention tool for emergency service volunteers'. The Australian Journal of Emergency Management. 2002; 17(3): 3-7.

8. Duffield, C. Macneil, F. Bullock, C. and Franks, H. 'The role of the Advanced Casualty Management Team in St John Ambulance Australia (New South Wales District)'. Australian Health Review. 2000; 23(1): 90-99.

9. O'Meara, PF. Models of ambulance service delivery for rural Victoria. PhD Thesis. The University of New South Wales. 2002.

10. Howard, BW. 'Managing volunteers'. Australian Journal of Emergency Management. Spring 1999: 37-38.

11. Checkland, P.B. Soft Systems Methodology: a 30-year retrospective. John Wiley \& Sons, Chichester. 1999.

12. Flood, RL. and Jackson, MC. Creative Problem Solving: Total Systems Intervention. John Wiley \& Sons, Brisbane. 1991.

13. Checkland, P.B. and Scholes, J. Soft Systems Methodology in Action. John Wiley \& Sons, Chichester. 1990.

14. Braithwaite, J. Handle, D. ledema, R. and Westbrook, JI. 'Introducing soft systems methodology plus (SSM+): why we need it and what it can contribute'. Australian Health Review. 2002; 25(2): 191-198.

15. Reinholtd, S. and Smith, P. Directions in volunteer development in Australian emergency services. Country Fire Authority, Victoria. 1998.

16. O'Meara, P. 'Professional and community expectations of Australian rural ambulance services'. Pre-hospital Immediate Care. 2001; 5:27-30.

17. Morgan, G. Images of Organization. Sage Publications, Thousand Oaks, Calif. 1997.

18. Kelly, H. O'Meara, P. and Burley, M. Urgent care in Victorian rural towns: Final Report. Monash University, Traralgon. 1999.

19. O'Meara, P. Burley, M. and Kelly, H. 'Urgent care systems: what are they made of? Australian Journal of Rural Health. 2002; 10(1): 45-51.

20. Norris, DF. Mandell, MB. and Hathaway, WE. 'Volunteers in Emergency Medical Service: A Case Study from Rural America'. Public Productivity and Management Review. 1993; 16: 257-69.

21. Payne, D. 'Poor ambulance response causes 700 deaths annually in Ireland'. British Medical Journal, 2000; 321: 1176.

This article was peer reviewed for the Journal of Emergency Primary Health Care Vol. 1 (1-2), 2003 